\title{
Does kindness always pay? The influence of recipient affection and generosity on young children's allocation decisions in a resource distribution task
}

\author{
Kirsten H. Blakey $^{1,2}$ - Erin Mason ${ }^{1}$ • Mioara Cristea ${ }^{1} \cdot$ Nicola McGuigan $^{1,3}$ (D) Emily J. E. Messer ${ }^{1,4}$
}

Published online: 24 April 2019

(C) The Author(s) 2019

\begin{abstract}
The aim of the current study was to determine whether the level of generosity shown by 3 - to 8 -year-old children $(N=136 ; M$ age $=69$ months) in a resource distribution task would vary according to whether the recipient had previously displayed kind (affection and generosity) and/or non-kind (non-affection and non-generosity) behavior towards a third party. We first asked whether donor children would show higher levels of generosity towards an affectionate than a non-affectionate recipient (condition 1), and a generous than a non-generous recipient (condition 2), before pitting the two forms of recipient kindness directly against each other (condition 3). Last, we asked whether donations to generous recipients would decrease if the recipient simultaneously displayed non-kind behavior through a lack of affection (condition 4). Here we show that children allocated a greater share of the available resource to generous and affectionate recipients than non-generous and non-affectionate recipients respectively. However, when asked to divide resources between a generous and an affectionate recipient, or two recipients who had each displayed a combination of kind and non-kind behavior, children allocated each recipient an equal share of the resource. These findings suggest that children donate selectively based on previous information regarding recipient generosity and affection, however when both forms of kindness are pitted directly against each other, children strive for equality, suggesting that kindness engenders donor generosity irrespective of the form of kindness previously displayed.
\end{abstract}

Keywords Resource distribution $\cdot$ Selective prosocial donating $\cdot$ Recipient characteristics $\cdot$ Indirect reciprocity

Behaving prosocially, that is acting to benefit others, is widespread amongst humans, with extreme levels of self-sacrifice, such as charitable donations to anonymous strangers frequently occurring (Fehr and Fischbacher 2003). The human capacity to cooperate, to help, and to share resources with others,

Electronic supplementary material The online version of this article (https://doi.org/10.1007/s12144-019-00260-7) contains supplementary material, which is available to authorized users.

Nicola McGuigan

Nicola.Mcguigan@uws.ac.uk

1 Department of Psychology, School of Social Sciences, Heriot-Watt University, Edinburgh EH14 4AS, UK

2 Department of Psychology, Faculty of Natural Sciences, University of Stirling, Stirling FK9 4LA, UK

3 Department of Psychology, School of Culture, Media and Society, University of the West of Scotland, Paisley PA1 2BE, UK

4 Department of Psychology, University of Texas at Austin, Austin, TX, USA contributes to the success of our socially motivated species, and, in part, facilitates our ability to live harmoniously in large social groups (e.g., Fehr and Fischbacher 2003). Unlike other species, humans frequently act prosocially not only to kin, but also to non-kin and even strangers (Daniel et al. 2015; Trommsdorff et al. 2007), a proclivity towards maintaining cooperation that is so strong that group members who display antisocial behavior are often punished or ostracized from the group (Herrmann et al. 2008; Kenward and Östh 2015; Korsgaard et al. 2010). Psychologists have long been interested in the developmental origins of such prosociality, with studies revealing complex developmental trajectories (Eisenberg and Fabes 1998), in which a capacity to help and cooperate, emerges before the ability to share resources (Brownell et al. 2013; House et al. 2012; Paulus and Moore 2014).

The developing capacity to share resources with others has recently stimulated a great deal of interest within the developmental literature, with researchers asking whether, and when, children show generosity in the distribution of resources. To address such questions, researchers have employed a variety 
of tasks adapted from those used in economic decisionmaking games, including simplified versions of the dictator and ultimatum games (e.g., Benenson et al. 2007; Blake and Rand 2010; Gummerum et al. 2008, 2010; Harbaugh and Krause 2000), and the prosocial choice test (e.g., Brownell et al. 2009; Claidiere et al. 2015; Dahlman et al. 2007; Fehr et al. 2008; House et al. 2012, 2013; Schmitz et al. 2015). The most common, although not exclusive (e.g., House et al. 2012), developmental pattern witnessed across tasks is one in which children become increasingly generous with age (e.g., Benenson et al. 2007; Blake and Rand 2010; Brownell et al. 2009; Gummerum et al. 2010), a pattern that is most evident in situations where the donor pays no direct or relative cost for their generosity (e.g., Dahlman et al. 2007; Fehr et al. 2008; Thompson et al. 1997). However, when presented with an unequal outcome that favors the recipient, donor children frequently opt for egalitarianism rather than generosity, an avoidance of inequality that becomes increasingly prevalent throughout early childhood (e.g. Fehr et al. 2008).

In addition to detailing whether, and when, children show generosity in their resource allocations, recent research has begun to examine young children's capacity for 'selective prosociality'. A suite of studies have shown that young children vary their level of generosity depending on characteristics of the recipient, including ingroup membership, moral deservedness, friendship, neediness, and status (Baumard et al. 2012; Malti et al. 2015; McGuigan et al. 2016). Specifically, children share more often with friends and high status individuals, than disliked peers and low status individuals, providing there is no personal cost for doing so (McGuigan et al. 2016; Moore 2009; Paulus and Moore 2014). Similarly, within the context of group membership, 3to 8 -year-old children donate more favorably to ingroup than outgroup members, with 7- and 8-year-olds also demonstrating an ingroup preference when incurring a personal cost for doing so (Fehr et al. 2008). Age-related selectivity has also been revealed with respect to moral deservedness and neediness, with both 4- and 8-year-old children allocating a greater share of an available resource to morally deserving and needy recipients, with 8-year-olds also allocating a substantially decreased share of the resource to a morally underserving recipient (Malti et al. 2015; Neldner et al. 2018). Taken together, these findings show that as early as the preschool period young children are selective donors, who adjust their level of generosity according to a variety of recipient characteristics, and that such generosity becomes increasingly selective as donors age.

Olson and Spelke (2008) employed a novel variation of the resource distribution paradigm in order to examine the evolutionary propensities, and social experiences, that may underpin young children's selective prosociality. More specifically, Olson and Spelke employed a 'forced choice recipient' paradigm that required $3 \frac{1}{2}$-year-old children to distribute, on behalf of a donor doll, a fixed number of resources between four recipient dolls. Of interest was whether young children's allocation decisions were influenced by three propensities that evolutionary theory would suggest favor the emergence of cooperation in humans: genetic relatedness, direct reciprocity, and indirect reciprocity. According to evolutionary theory, donors should allocate a greater share of an available resource to close kin (Hamilton 1964), to individuals who have shared with them previously (direct reciprocity: A helps B because B has helped A previously; Trivers 1971), and to individuals who have previously shared with others (indirect reciprocity: A helps B because B is known to have helped C previously; Nowak and Sigmund 2005; Trivers 1971). Olson and Spelke introduced the possibility of reciprocity by allowing the participants to observe, prior to making their allocation decision, a demonstration in which each recipient was observed either giving, or not giving, a resource to a third party. The beneficiary of the generous behavior in the demonstration was varied (directed to either the 'donor' doll or a neutral doll) allowing the opportunity for direct and indirect reciprocity. The results showed that as well as donating preferentially to kin, $3 \frac{1}{2}$-year-old children demonstrated both forms of reciprocity, donating with high levels of generosity to recipients who had shared with the donor doll previously (direct reciprocity), and to recipients who had been observed sharing with the neutral doll (indirect reciprocity). Thus, when distributing resources amongst a fixed number of recipients, children's allocation decisions appear to be influenced by exposure to information regarding the recipient's prior behavior.

The aim of the current study was to utilize the 'forced choice recipient' paradigm employed by Olson and Spelke (2008) to determine whether reciprocal displays of generosity vary in response to two different forms of kindness (generosity in the form of sharing and affection in the form of hugging). In contrast to Olson and Spelke who provided donors only with information regarding recipient behavior that was related to the context of resource distribution (i.e., the recipient's history of generosity), we included demonstrations in which the recipient's prior behavior was either related (i.e., the donor observed the recipient's prior level of (non)generosity towards a third party) or unrelated (i.e., the donor observed the recipient's prior level of (non) affection towards a third party) to resource distribution. Our main motivation in making this contrast was to determine whether the reputation monitoring that is believed to underpin indirect reciprocity is best established through 'payment-in-kind' (i.e., a resource-for-a resource payment structure), or whether 
any positive reputation can result in generosity from a donor (i.e., a resource-for-kindness payment structure). If as theorized, indirect reciprocity leads to cooperation through an expectation of future help, that is based on previous experiences/ interactions with other individuals (Rutte and Taborsky 2007), then it may be the case that prior displays of generosity would be a more accurate predictor of future generosity than affection.

It is also possible that the strength of the cooperative reputation that is established by engaging in observable acts of kindness varies according to how costly that behavior is perceived to be by observers. Costly signaling theory proposes that observable displays of costly prosocial acts are used by individuals to advertise a cooperative reputation, a reputation that benefits the 'displaying' individual through improved access to cooperative relationships and greater cooperation within these relationships (Barclay and Willer 2007; Bradley et al. 2018). It may be that public displays of generosity in which the individual incurs a direct cost as a consequence of their kindness (i.e., the loss of a resource) sends a more powerful signal of cooperative intent than does a public display of affection which by comparison is relatively low cost. Thus, by introducing two different forms of kindness into the context of resource distribution we aimed to provide novel insight into whether indirect reciprocity is underpinned by a highly specific, or more generalized, notion of reputation that is related to the perceived cost of the action.

More specifically, we first asked whether children would demonstrate a general preference for donating to a kind recipient than a non-kind recipient (affectionate vs. nonaffectionate recipient; generous $v$ non-generous recipient), before pitting the two different forms of kindness against each other (generous vs. affectionate recipient). In our final condition, by employing combinations of kind/non-kind behaviors, we aimed to determine, whether any preferential donating shown towards a generous recipient would decrease if the recipient simultaneously displayed non-kindness (a lack of affection). It was predicted that participants would allocate a greater share of the available resource to a kind than a nonkind recipient irrespective of the form of kindness on display (affection or generosity). When generous and affectionate recipients were pitted directly against each other, we predicted that the participants would allocate a greater share of the available resource to the generous recipient, as prior displays of generosity provided the donor with information that was related to the context of resource distribution. In our final comparison, we predicted that children would donate preferentially to a generous, but non-affectionate, recipient than to a nongenerous, but affectionate recipient, as the generous recipient's prior level of generosity when distributing resources would take precedence over kindness displayed in a different, less relevant, form. Finally, we predicted that there would be age differences in donating behavior with older children demonstrating greater levels of selectivity in their donating decisions than the younger children.

\section{Method}

\section{Participants}

One hundred and thirty-six (68 males) 3- to 8-year-old children $(M$ age $=69.06$ months, range $=35$ to 106 months, $S D=$ 19.45 months) were allocated to one of four conditions (see Table 1 for a full breakdown of participant information). An additional 38 children were excluded from the study due to having failed the training phase $(N=8)$, having provided incorrect answers to the comprehension check in the demonstration phase $(N=22)$, or having become distracted during the experiment $(\mathrm{N}=8)$. Participants were predominantly Caucasian and were recruited from kindergarten and elementary schools in Scotland, UK that served a broad socioeconomic area. Informed consent was obtained from the parent/ legal guardian of each child prior to their participation in the study.

\section{Design}

In a between-participants design, children were assigned to one of four conditions, in which they viewed two actors each display kind (generous or affectionate) and/or non-kind (nongenerous or non-affectionate) behavior towards a third party. Generous and non-generous behavior was evidenced by an actor either donating, or withholding, a resource from a third party, whereas affection and non-affection was evidenced by an actor either hugging, or not hugging, a third party. In conditions 1 and 2, we pitted a kind actor against a non-kind actor (condition 1: affectionate $(\mathrm{A}+)$ actor vs. non-affectionate $(\mathrm{A}-)$ actor; condition 2: generous (G+) actor vs. non-generous (G-) actor), whereas in Condition 3 we pitted the two forms of kindness directly against one another (affectionate $(\mathrm{A}+)$ actor vs. generous (G+) actor). The fourth condition pitted together a combination of both kind and non-kind behaviors, such that one actor demonstrated themselves to be both affectionate and non-generous $(\mathrm{A}+/ \mathrm{G}-)$, with the other actor displaying a lack of affection but demonstrating generosity $(\mathrm{A}-/ \mathrm{G}+)$.

Each of the four conditions comprised three phases: a training phase, a demonstration phase, and a test phase (see Fig. 1 for an illustration of the task set-up in each phase). The training phase was designed to familiarize the participants with the 
Table 1 Participant details broken down by condition (A+: Affectionate; A-: non-affectionate; G+: Generous; G-: non-generous) and age group. Standard deviations are provided in parenthesis. $\mathrm{M}=$ Male, $\mathrm{F}=$ Female

\begin{tabular}{|c|c|c|c|c|c|c|c|c|c|}
\hline \multirow[t]{2}{*}{ Condition } & \multicolumn{3}{|c|}{ All ages } & \multicolumn{3}{|c|}{3 to 5 years } & \multicolumn{3}{|c|}{6 to 8 years } \\
\hline & $\mathrm{N}$ & $\mathrm{M} / \mathrm{F}$ & $M$ Age & $\mathrm{N}$ & $\mathrm{M} / \mathrm{F}$ & $M$ Age & $\mathrm{N}$ & $\mathrm{M} / \mathrm{F}$ & $M$ Age \\
\hline 1 A+ vs. A- & 34 & $15 / 19$ & 68.09 (19.74) & 19 & $8 / 11$ & $53.74(9.44)$ & 15 & $7 / 8$ & $86.27(13.06)$ \\
\hline 2 G+ vs. G- & 32 & $15 / 17$ & $69.22(19.95)$ & 17 & $11 / 6$ & $53.65(9.60)$ & 15 & $4 / 11$ & $86.87(12.15)$ \\
\hline 3 A+ vs. G+ & 30 & $15 / 15$ & $72.10(20.51)$ & 15 & $8 / 7$ & $53.93(8.85)$ & 15 & $7 / 8$ & $90.27(9.26)$ \\
\hline $4 \mathrm{~A}-/ \mathrm{G}+\mathrm{vs} . \mathrm{A}+/ \mathrm{G}-$ & 40 & $23 / 17$ & $67.48(18.45)$ & 25 & $14 / 11$ & $54.84(8.35)$ & 15 & $9 / 6$ & $88.53(8.25)$ \\
\hline Overall & 136 & $68 / 68$ & $69.06(19.45)$ & 76 & $41 / 35$ & $54.12(8.85)$ & 60 & $27 / 33$ & $87.98(10.70)$ \\
\hline
\end{tabular}

task structure to be used in the test phase, and required the participants to complete a series of trials in which they were asked to allocate a single reward to one of two recipients (different from those to be employed in the test phase). Participants who successfully completed training moved to the demonstration phase in which they observed two actors each display a different set of kind and non-kind behaviors towards a third party, with the specific behaviors on display varying according to condition (1, 2, 3, or 4). Following the demonstration phase, the participants undertook a test phase, comprised of six trials, in which they were asked to allocate a single reward to one of the two actors from the demonstration phase (who now acted as recipients). The participants were unaware of how many trials they would be required to complete in the test phase.

\section{Materials}

The training phase required the use of two soft toys (a leopard and an elephant), three identical sticker cups (one each for the toys and the participant), and pairs of identical (sticker) rewards. The demonstration phase required the use of three soft toys (two bears and a monkey) different to those used in the training phase. The two bears, who differed only in the color of their clothing acted out the behavioral characteristics of interest in each of the four conditions, with the remaining toy (a monkey) acting as the third party upon which the actors bestowed their actions. In the three conditions $(1,3, \& 4)$ that involved the actor displaying generosity/non-generosity, the item to be donated to (or withheld from) the third party was a cardboard banana. The test phase employed the two actors from the demonstration phase as recipients (the two bears), the three sticker cups from the training phase (one for each of the toys and the participant), and six pairs of identical sticker rewards.

\section{Procedure}

Training Phase The training phase was designed to familiarize the participants with the task structure that they would experience in the test phase (see Fig. 1 panel a). At the outset of training, the participants were introduced to two toys, "This is leopard, and this is elephant", that were positioned side-byside (position counterbalanced across trials) directly opposite
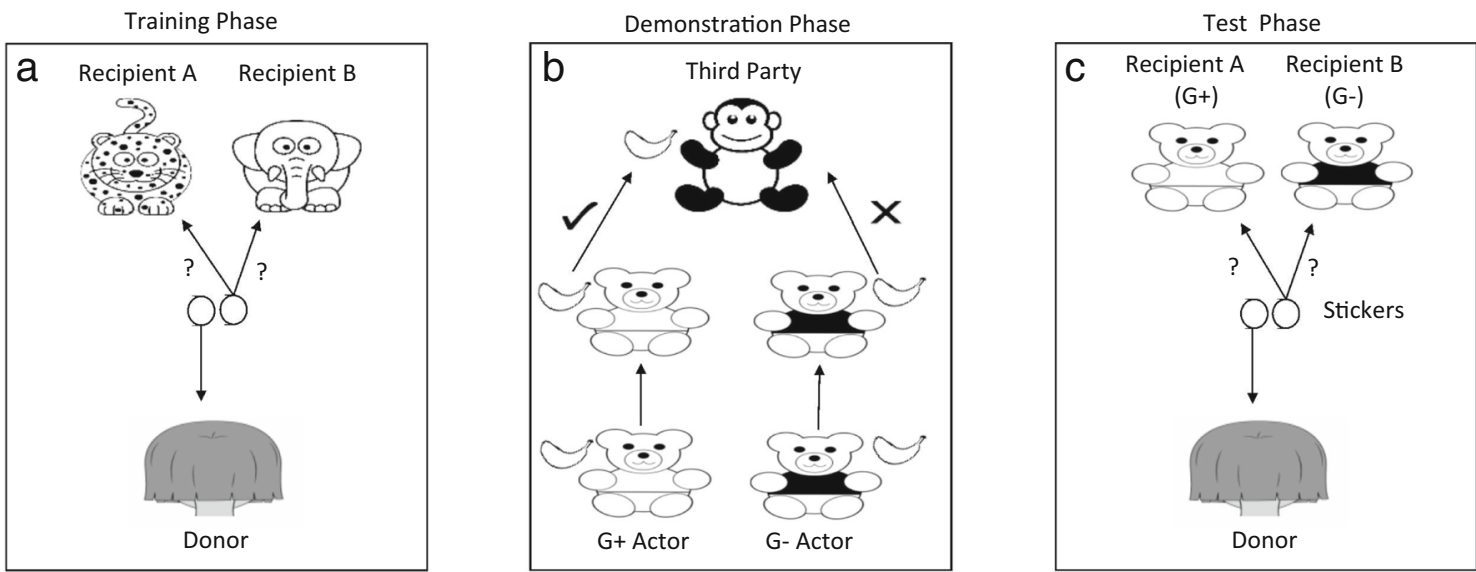

Fig. 1 Illustration of the task set-up used in the training, demonstration, and test phases. Note. Figure shows the configuration employed in condition 2 (generous $(\mathrm{G}+)$ vs. non-generous $(\mathrm{G}-)$ recipient 
the participant. Following the introductions, the experimenter positioned a sticker cup in front of the participant and each of the toys, then placed two identical stickers in the center of the table. The participant was asked to select one sticker for themselves and to place it in their sticker cup, next they were asked to choose which of the two toys should receive the remaining sticker, "Now you can choose who to give the other sticker to". Once the participant had placed the sticker in the chosen recipient's sticker cup the experimenter checked for task understanding by asking the participant to indicate whether a sticker had been allocated to each toy, "Does elephant have a sticker? Does leopard have a sticker?" To proceed to the demonstration phase the participants were required to indicate correctly which toy had been allocated the sticker on two consecutive trials (from a maximum of four).

Demonstration Phase In all four conditions the experimenter acted out a scenario in which two actors (toy bears) engaged in kind or non-kind (or a combination of the two) behavior(s) towards a third party (a toy monkey). Within each condition the behavior of each actor varied according to whether they displayed (non) affection and/or (non)generosity (see Fig. 1 panel b). The experimenter indicated affection in an actor by first moving the actor towards, and subsequently hugging, the monkey, whereas a lack of affection was indicated by the actor approaching, but not hugging, the monkey. In demonstrations involving generosity, the actor carried a banana towards the monkey, and either donated the banana to the monkey (generous actor) or kept the banana for themselves (non-generous actor). To ensure that the participants did not have a general preference for one toy bear over the other, the behavioral characteristic(s) displayed by each of the toys during the demonstration was counterbalanced across participants. As a comprehension check, upon completion of the demonstration each participant was asked to recall the behavioral characteristic(s) displayed by each of the two actors, e.g., "Can you show me which teddy was sharing teddy, and which was not-sharing teddy?", with the order of questioning regarding the first and second actor's behavior counterbalanced.

Test Phase Once the demonstration was complete, the two actors (hereafter, recipients A and B) were positioned directly opposite the participant and a sticker cup was placed in front of each (see Fig. 1 panel c). Following the same procedure used in the training phase, the experimenter then placed two identical stickers on the table and instructed the participant to select one sticker for themselves and allocate the remaining sticker to one of the two recipients, "Now you [the child] are going to give out stickers again, you [the child] can keep one and choose which teddy gets the other sticker". The participants completed six trials in the test phase, with each recipient being positioned on both the left and right sides an equal number or times (order randomized). To aid the participants' task understanding the behavioral characteristic(s) displayed by each actor during the demonstration were indicated verbally at the outset of each trial, e.g., "This time sharing teddy [generous actor] will go here and not-sharing [non-generous actor] teddy will go here".

\section{Results}

We present a series of increasingly detailed analyses that aimed to determine whether children displayed a different pattern of resource donation depending on the set of behavioral characteristics displayed by each pair of recipients. Within each of the four conditions we first asked whether children donated a greater share of the available resource $(6$ stickers) to Recipient A or Recipient B, before considering both the overall donating strategy (mean, prosocial, or egalitarian), and the trial-by-trial strategy adopted. Preliminary analyses revealed that there was no effect of donor gender in any of the four conditions therefore donor gender was excluded from all subsequent analyses.

\section{Did Children Show Selective Resource Donation?}

Of primary interest in the analysis was whether the participants would show a preference for one recipient over the other when allocating rewards, and whether reward allocation frequency varied according to the specific behavioral characteristics displayed by each pair of recipients. When presented with a choice to donate to either a kind or an non-kind recipient children allocated a significantly greater proportion of the rewards to the kind recipient in both condition $1(M \mathrm{~A}+=.59$, $M \mathrm{~A}-=.41$; two tailed binomial test: $p=.009$; see Fig. 2 panel a) and condition $2(M \mathrm{G}+=.59, M \mathrm{G}-=.41$; two tailed binomial test: $p=.017$; see Fig. 2 panel b). However, the frequency with which the children allocated rewards to the kind recipient varied with donor age with the older children displaying a preference for the affectionate recipient over the nonaffectionate recipient $(6-8$ years: $M \mathrm{~A}+=.61, M \mathrm{~A}-=.39$; two tailed binomial test: $p=.045$; see Fig. 2 panel a). Whereas, the younger children preferred to donate to the generous recipient than the non-generous recipient (3-5 years: $M$ $\mathrm{G}+=.66, M \mathrm{G}-=.34$; two tailed binomial test: $p=.002$; see Fig. 2 panel b). In contrast, in conditions 3 and 4 when having viewed two recipients each display a different form of kindness (A+ vs. G+: condition 3), or having viewed two recipients each display a combination of both kind and non-kind behaviors (A+/G- vs. A-/G+: condition 4), children from both 

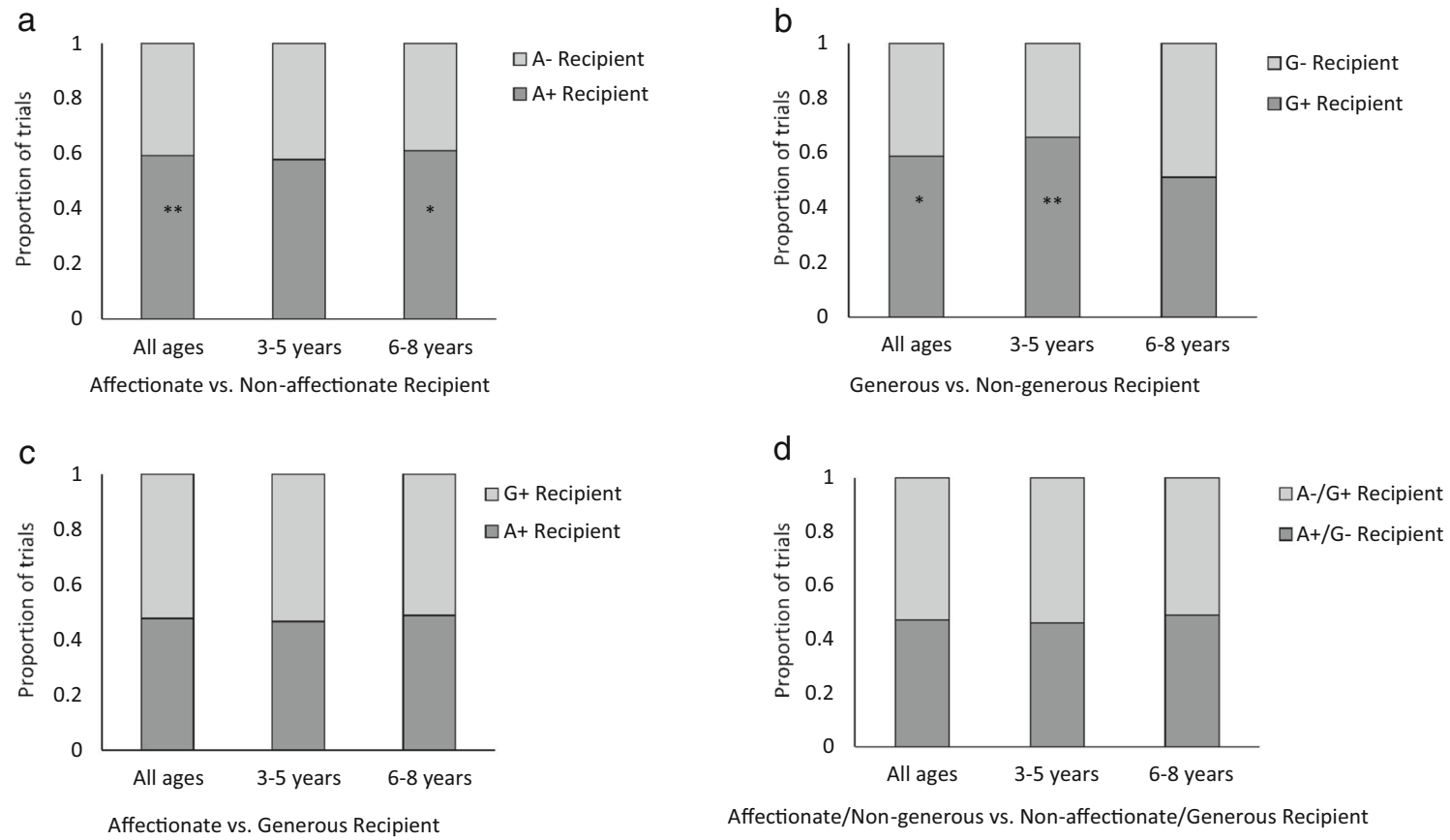

Affectionate/Non-generous vs. Non-affectionate/Generous Recipient

Fig. 2 Proportion of trials in which the resource was donated to Recipient A and Recipient

age groups divided the resource equally between the two recipients (see Fig. 2 panels $\mathrm{c}$ and d).

\section{Did Children Employ Different Donation Strategies?}

To more fully detail the way in which children allocated resources within each condition, the total number of donations made to Recipient A were categorized into three different donating strategies (prosocial, mean, or egalitarian). Those donors who displayed a 'mean' donating strategy donated 0,1 , or 2 rewards to A (i.e., A received fewer rewards than B), those children who donated 'prosocially' allocated 4, 5, or 6 rewards to A (i.e., A received more rewards than B), with those children who were 'egalitarian' donating 3 rewards to both A and B. For the purposes of the analysis Recipient A was deemed the affectionate recipient in condition 1 , the generous recipient in condition 2 , the affectionate recipient in condition 3, and the affectionate/non-generous recipient in condition 4. The donations made towards Recipient B were not considered in the following analyses as B's allocation was the inverse of that allocated to A.

A chi square analysis that compared the number of children displaying the three donation strategies in each of the four conditions revealed that the pattern of donating differed significantly across conditions $\left(\chi^{2}(6)=18.13, p=.005\right.$; see Fig. 3). In order to determine where the condition differences lay, we conducted a series of follow-up binomial tests that compared the frequency with which each strategy was employed in each condition. These analyses revealed that in conditions $1(\mathrm{~A}+$ vs. A-) and 2 (G+ vs. G-) the children were equally likely to adopt a mean, an egalitarian, or a prosocial strategy. The single exception occurred in condition 1 where the children adopted a mean strategy significantly less often than would be expected by chance (condition $1 M$ mean = .12; two tailed binomial: $p=.008$; see Fig. 3). More detailed analysis of the donating behavior of the different age groups indicated that the infrequent adoption of a mean approach in condition 1 was primarily driven by the younger children (35 years) who, in contrast to their older (6-8 years) counterparts, adopted a mean strategy significantly less often than would be expected by chance (3-5 years: condition $1 \mathrm{M}$

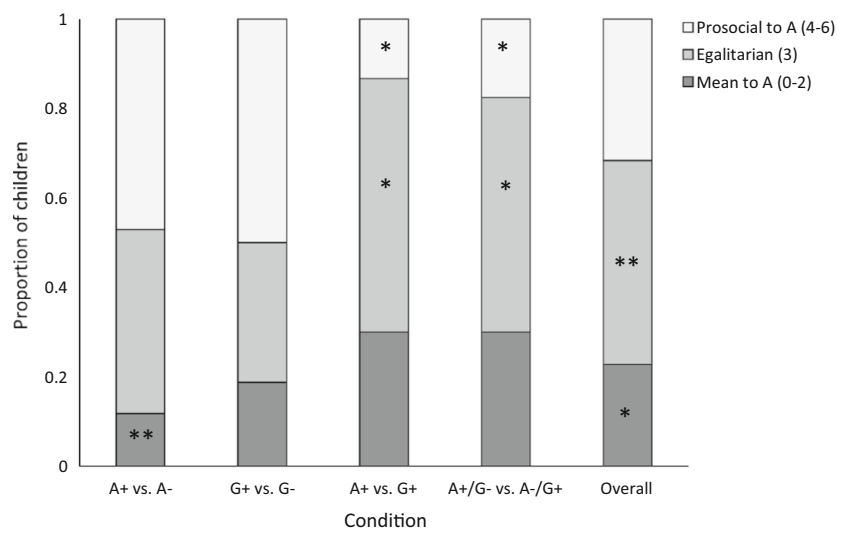

Fig. 3 Proportion of children that displayed each of the three patterns of donating behavior towards Recipient A 
mean $=.11$; two tailed binomial: $p=.048$; see supplementary Fig. 1).

In contrast to the donating pattern witnessed in conditions 1 and 2 the donors in both condition $3(\mathrm{G}+\mathrm{vs} . \mathrm{A}+$ ) and condition 4 (A+/G- vs. A-/G+) were significantly more likely to adopt an egalitarian strategy (condition $3: M$ egalitarian $=.57$; two tailed binomial: $p=.012$; condition 4: $M$ egalitarian $=.53$; two tailed binomial test: $p=.016$; see Fig. 3), and significantly less likely to employ a prosocial strategy (condition 3: $M$ prosocial $=.13$; two tailed binomial test: $p=.026$; condition 4: $M$ prosocial $=.18$; two tailed binomial test: $p=.046$; see Fig. 3), than would be expected by chance. Analysis of the approach adopted by the different age groups revealed that the high levels of egalitarianism, and the lack of prosociality, witnessed in condition 3 was primarily driven by the older children who adopted an egalitarian strategy significantly more often (condition 3: 6-8 years $M$ egalitarian $=.80$; two tailed binomial test: $p<.001$; see supplementary Fig. 2), and a prosocial strategy significantly less often (condition 3: 68 years $M$ prosocial $=.07$; two tailed binomial test: $p=.038$; see Supplementary Fig. 2) than would be expected by chance. In contrast, the younger children were equally likely to adopt a prosocial, an egalitarian, or a mean strategy in condition 3 (see Supplementary Fig. 1). Neither the younger nor the older children showed a donating strategy preference in condition 4 (see Supplementary Figs. $1 \& 2$ ).

\section{Did Children Alternate Resources between Recipients?}

In addition to detailing whether children varied in their broad approach to donation we were also interested in the way that children allocated resources at the trial level. In instances where the rewards were distributed equally between the two

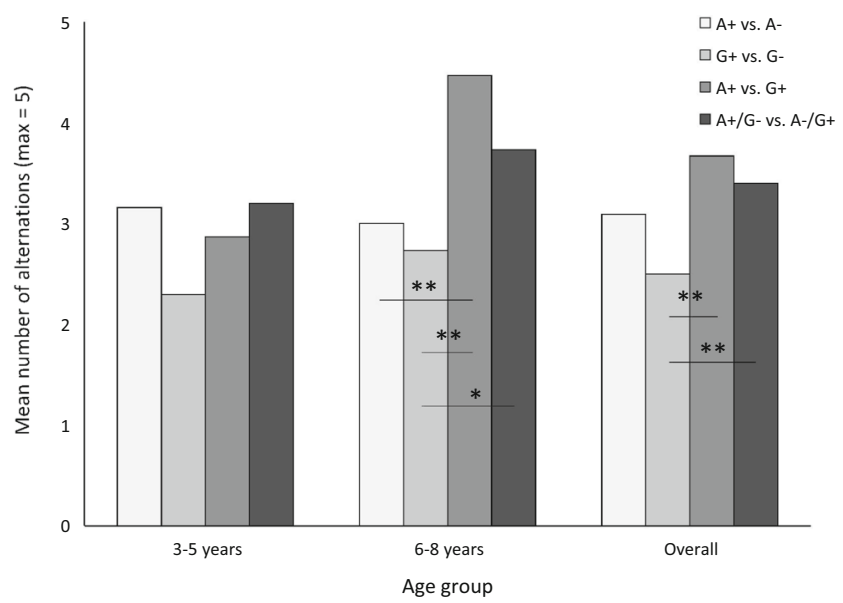

Fig. 4 Mean number of alternating donations made to Recipients A and B as a function of donor age recipients, equality could have been achieved in a variety of ways: 1) by allocating first $\mathrm{A}$ and then $\mathrm{B}$, three rewards (AAABBB), 2) alternating the recipient of the reward on every trial (e.g., ABABAB), or 3) a mixture of the two (e.g., ABBAAB). To determine whether, and if so, how frequently children shifted their allocation between recipients we calculated an 'alternation score' for each child that could range from 0 to 5 . Higher scores reflected a greater tendency of the donor to alternate between $\mathrm{A}$ and $\mathrm{B}$, with those individuals who achieved a score of 5 alternating between $\mathrm{A}$ and $\mathrm{B}$ on every trial, and those individuals who never alternated receiving a score of 0 .

The frequency with which the participants alternated their donations was examined using a univariate ANOVA with each donor's alternation score (0-5) as the dependent variable, and condition $(1,2,3$, or 4$)$ and age group (3-5 years or 6-8 years) as the between participants factors. The analysis revealed a significant main effect of condition $(\mathrm{F}(3,128)=4.71$, $p=.004, \mu=.10$; see Fig. 4), with follow-up post hoc Tukey tests indicating that the donors in condition $2(\mathrm{G}+$ vs. G- $M$ alternation $=2.50$ ) alternated resources between recipients significantly less often than the donors in both condition 3 $(\mathrm{A}+$ vs. $\mathrm{G}+M$ alternation $=3.67 ; p=.001)$ and condition 4 $(\mathrm{A}+/ \mathrm{G}-\mathrm{vs} . \mathrm{A}-/ \mathrm{G}+M$ alternation $=3.40, p=.005)$. The analysis also revealed a significant main effect of age group $(\mathrm{F}(1,128)=6.891, p=.010, \mu=.051)$, with the older children $(6-8$ years $M$ alternation $=3.48)$ alternating between recipients more frequently than the younger children (3-5 years $M$ alternation $=2.92$ ), indicating an increased tendency of the older children to maintain equality on a trial-by-trial basis.

To explore the influence of donor age on alternation frequency in more detail we conducted a two further ANOVAs (one for each age group). The analysis of the donating behavior of the younger children revealed that the 3- to 5-year-olds alternated at equivalent levels across conditions irrespective of the combination of recipient characteristics displayed $(\mathrm{F}(3,72)=1.92, p=.13, \mu=.07$; see Fig. 4). In contrast, the alternation pattern of the older children varied significantly across conditions $(\mathrm{F}(3,56)=5.03, \mathrm{p}=.004, \mu=.21$; see Fig. 4). Follow up post hoc Tukey tests revealed that the 6- to 8year-olds alternated more frequently in condition 3 (A+ vs. $\mathrm{G}+M$ alternation $=4.47)$ than in condition $1(\mathrm{~A}+\mathrm{vs}$. $\mathrm{A}-M$ alternation $=3.00, \mathrm{p}=.004)$ and condition $2(\mathrm{G}+\mathrm{v} \mathrm{G}-M=$ $2.73, \mathrm{p}=.001)$, and more frequently in condition $4(\mathrm{~A}+/ \mathrm{G}-$ vs. A-/G+ $M$ alternation $=3.73$ ) than condition $2(\mathrm{G}+$ vs. G$M$ alternation $=2.73, p=.047$; see Fig. 4). This donating pattern suggests that when presented with two recipients who had each displayed a form of kindness, in the context of an unknown number of trials, the older, but not the younger, children maintained equality on a trial-by-trial basis. 


\section{Discussion}

Previous studies have shown that preschool children can, in some contexts, act generously when donating resources to others (e.g., Brownell et al. 2009; Sebastián-Enesco et al. 2013), and that such generosity is on occasion displayed selectively (e.g., Fehr et al. 2008; Moore 2009), before becoming increasingly fine-grained, and less dependent on the outcome for the donor themselves (e.g., Malti et al. 2015; McGuigan et al. 2016). The current study built on this previous research by providing a novel test of indirect reciprocity in which different forms of recipient (non) kindness were pitted against each other. In line with predictions, when tasked with distributing resources between a kind and a non-kind recipient, the donors allocated a significantly greater proportion of the available resource to the kind recipient, irrespective of whether the behavior on display was generosity or affection. However, counter to predictions, when both recipients had displayed kindness, either in isolation or in combination with non-kindness, the donors distributed the resources equally between the recipients, suggesting that each form of kindness, although varying in the direct cost incurred, was equally valued by the observing individual. Indeed, the strength of the drive towards equality in these latter instances was evidenced at the trial level, where donors frequently maintained equality on a trial-by-trial basis, in doing so strategically rewarding each form of kindness displayed.

That children demonstrated elevated levels of generosity towards kind recipients suggests that the donors were bestowing a 'reputation' upon each recipient, a monitoring process consistent with indirect reciprocity (Nowak and Sigmund 2005). Indirect reciprocity involves individuals acquiring, and acting upon, knowledge of their partner's past cooperative behavior (House et al. 2013), and comes in two forms - upstream and downstream. Upstream reciprocity occurs in instances where $\mathrm{B}$ responds to a helpful act received from A by becoming more likely to direct a helpful act towards $\mathrm{C}$, whereas 'downstream reciprocity' occurs in those instances where having helped $\mathrm{B}, \mathrm{A}$ is more likely to be helped by others (Nowak and Roch 2007). In the context of the current study, the participants appeared to be engaging in downstream reciprocity with the donor reciprocating the kind recipient's prior display of generosity or affection. This developing capacity to engage in downstream indirect reciprocity is consistent with the results of previous studies that show indirect reciprocity in resource distribution tasks (Olson and Spelke 2008), and extends previous research to show that indirect reciprocity can occur in response to displays of kindness that are not related to resource distribution. The current findings also add to the broad literature which suggests that young children's donating decisions are underpinned by a variety of reciprocity mechanisms, including upstream indirect reciprocity (Claidiere et al. 2015) and direct reciprocity (Messer et al. 2017; House et al. 2013; Olson and Spelke 2008; Sebastián-Enesco et al. 2013; Warneken and Tomasello 2013).

Moreover, the pattern of reciprocity witnessed in the current study was influenced by the age of the donor. When presented with both an affectionate and a non-affectionate recipient 6- to 8-year-olds, but not 3- to 5-year-olds, allocated a greater share of the resources to the affectionate recipient. This donation pattern is consistent with a developmental trajectory in which the older children were more aware of, and were more likely to act upon, (non) kind recipient characteristics than their younger counterparts, a finding that is consistent with the age-related differentiation of sharing witnessed in previous studies (e.g., Fehr et al. 2008; Malti et al. 2015; McGuigan et al. 2016). In contrast, and somewhat surprisingly, the opposite pattern emerged with respect to recipient generosity, with the younger, but not the older, children allocating a greater share of the resource to the generous recipient. These age differences may have arisen as a consequence of the older children viewing the resource as belonging to the actor, and therefore regarding the withholding of the resource as justifiable. Indeed, consistent with this suggestion, recent studies that employed an 'ownership sorting paradigm' demonstrated an increasingly differentiated notion of self and other ownership, coupled with an increased awareness of other ownership, across the early years period (Cunningham et al. 2014).

In contrast to the developmental differences witnessed in response to displays of kind versus non-kind behavior, the pattern of performance in those conditions where the recipients both displayed kind behavior, appeared on the surface at least, to be less influenced by donor age. Although children from both age groups allocated an equal number of rewards to each recipient, more detailed analysis of the broad strategy adopted, and the trial-by-trial pattern of donation, suggests that the donation decisions of the older children showed greater complexity. Specifically, the older children favored an egalitarian approach that was frequently underpinned by the alternation of the reward recipient on a trial-by-trial basis, indicating a strategic attempt (across an unknown number of trials) to maintain equality between two 'equally worthy' recipients. This drive towards equality in our older participants is consistent with recent resource distribution studies that demonstrated age-related increased aversion to inequity (Blake and McAuliffe 2011), alongside a growing preference for egalitarianism, 'fairness', and consideration of others (Fehr et al. 2008; Ongley et al. 2014), as well as with broad theories of distributive justice (Damon 1975; Enright et al. 1984). 
Taken together, these age-related changes in generosity suggest that the older children were basing their donating decisions on a more generalized notion of reputation (including considerations of both generosity and affection) than their younger counterparts, whose notion of reputation appeared highly restricted (i.e., actors were only shown generosity in response to prior generosity). The developmental pattern witnessed may be a consequence of the acquisition of complex cognitive, social, emotional, and individual factors that have yet to develop in the youngest participants. These factors include advancements in theory-of-mind (Malti et al. 2015; Wellman et al. 2001), an increased awareness of moral emotion expectancies (Krettenauer et al. 2008), an increased awareness of own reputation (Dana et al. 2006; Olson and Spelke 2008), a greater capacity to respond with sympathy (Malti et al. 2007, 2009), as well as through increased opportunity to acquire 'fairness' norms from individuals in their social environment (Eisenberg and Mussen 1989). Future research should usefully explore the relationship between the developing cognitive and socio-cognitive abilities that underpin young children's allocation decisions, and the ability of young children to engage in the various forms of reciprocity that underpin cooperation.

In sum, when asked to distribute rewards between two recipients who each displayed different combinations of kind and non-kind characteristics children's donating decisions were influenced both by the form of (non) kindness displayed by the recipients and by the age of the donor themselves. That our young donors engaged in indirect reciprocity, even in instances where displays of kindness were unrelated to resource donation, provides support for accounts from the biological literature that propose an adaptive function for reputation monitoring in aiding cooperation between nonrelatives within human social groups (Engelmann and Fischbacher 2009; Greiner and Levati 2005; Nowak and Sigmund 1998; Seinen and Schram 2006). Through showing that young humans, in simple one-shot interactions, can monitor, and act upon, the behavior of third parties our study provides important insight into whether, and how, 3- to 8-year-old children reciprocate kind actions. That such capacity for reputation-based reciprocity is evident early in development would appear to provide testament to the utility of downstream reciprocity in maintaining cooperation in human societies under conditions in which repeated interactions between non-relatives may not be possible.

Acknowledgements We thank the John Templeton Foundation for funding the project and the schools, teachers, parents/guardians and children who participated in the study.
Compliance with Ethical Standards This study was supported by a grant from the John Templeton Foundation (Ref\#48186). The funders had no role in study design, data collection, data analysis, decision to publish, or preparation of the manuscript.

Ethical Approval Ethical approval was granted by the School of Life Science Ethics Committee at Heriot-Watt University, UK. All procedures were conducted in accordance with the relevant guidelines and regulations.

Informed Consent Informed consent was obtained from the parents/ guardians of all children prior to their participation in the study.

Conflict of Interest The authors declare no conflicts of interest.

Open Access This article is distributed under the terms of the Creative Commons Attribution 4.0 International License (http:// creativecommons.org/licenses/by/4.0/), which permits unrestricted use, distribution, and reproduction in any medium, provided you give appropriate credit to the original author(s) and the source, provide a link to the Creative Commons license, and indicate if changes were made.

\section{References}

Barclay, P., \& Willer, R. (2007). Partner choice creates competitive altruism in humans. Proceedings of the Royal Society B, 274, 749-753. https://doi.org/10.1098/rspb.2006.0209.

Baumard, N., Mascaro, O., \& Chevallier, C. (2012). Preschoolers are able to take merit into account when distributing goods. Developmental Psychology, 48, 492-498. https://doi.org/10.1037/a0026598.

Benenson, J. F., Pascoe, J., \& Radmore, N. (2007). Children's altruistic behavior in the dictator game. Evolution and Human Behavior, 28, 168-175. https://doi.org/10.1016/j.evolhumbehav.2006.10.003.

Blake, P. R., \& McAuliffe, K. (2011). "I had so much it didn't seem fair": Eight-year-olds reject two forms of inequity. Cognition, 120, 215224. https://doi.org/10.1016/j.cognition.2011.04.006.

Blake, P. R., \& Rand, D. G. (2010). Currency value moderates equity preference among young children. Evolution and Human Behavior, 31, 210-218. https://doi.org/10.1016/j.evolhumbehav.2009.06.012.

Bradley, A., Lawrence, C., \& Ferguson, E. (2018). Does observability affect prosociality? Proceedings of the Royal Society B, 285, 20180116. https://doi.org/10.1098/rspb.2018.0116.

Brownell, C. A., Svetlova, M., \& Nichols, S. (2009). To share or not to share: When do toddlers respond to anothers needs? Infancy, 14, 117-130. https://doi.org/10.1080/15250000802569868.

Brownell, C. A., Iesue, S. S., Nichols, S. R., \& Svetlova, M. (2013). Mine or yours? Development of sharing in toddlers in relation to ownership understanding. Child Development, 84, 906-920. https://doi. org/10.1111/cdev. 12009.

Claidiere, N., Whiten, A., Mareno, M. C., Messer, E. J. E., Brosnan, S. F., Hopper, L. M., Lambeth, S. P., Schapiro, S. J., \& McGuigan, N. (2015). Selective and contagious prosocial resource donation in capuchin monkeys, chimpanzees and humans. Scientific Reports, 5, 111. https://doi.org/10.1038/srep07631.

Cunningham, S. J., Brebner, J. L., Quinn, F., \& Turk, D. J. (2014). The self-reference effect on memory in early childhood. Child Development, 85, 808-823. https://doi.org/10.1111/cdev.12144. 
Dahlman, S., Ljungqvist, P., \& Johannesson, M. (2007). Reciprocity in young children. SSE/EFI Working Paper Series in Economics and Finance (No. 674), Stockholm School of Economics.

Damon, W. (1975). Early conceptions of positive justice as related to the development of logical operations. Child Development, 46, 301312. https://doi.org/10.2307/1128122.

Dana, J., Cain, D. M., \& Dawes, R. M. (2006). What you don't know won't hurt me: Costly (but quiet) exit in dictator games. Organizational Behavior and Human Decision Processes, 100, 193-201. https://doi.org/10.1016/j.obhdp.2005.10.001.

Daniel, E., Bilgin, A. S., Brezina, I., Strohmeier, C. E., \& Vainre, M. (2015). Values and helping behavior: A study in four cultures. International Journal of Psychology, 50, 186-192. https://doi.org/ 10.1002/ijop.12086.

Eisenberg, N., \& Fabes, R. A. (1998). Prosocial development. In N. Eisenberg \& W. Damon. (Eds.), Social, Emotional and Personality Development. Volume 3 of the Handbook of child psychology (5th ed., pp. 701-778). New York: Wiley.

Eisenberg, N., \& Mussen, P. H. (1989). The roots of prosocial behavior in children. Cambridge: Cambridge University Press

Engelmann, D., \& Fischbacher, U. (2009). Indirect reciprocity and strategic reputation building in an experimental helping game. Games and Economic Behavior, 67, 399-407. https://doi.org/10.1016/j.geb. 2008.12.006

Enright, R. D., Bjerstedt, A., Enright, W. F., Levy, V. M., Lapsley, D. K., Buss, R. R., Harwell, M., \& Zindler, M. (1984). Distributive justice development: Cross-cultural, contextual, and longitudinal evaluations. Child Development, 55, 1737-1751. https://doi.org/10.2307/ 1129921.

Fehr, E., \& Fischbacher, U. (2003). The nature of human altruism. Nature, 425, 785-791. https://doi.org/10.1038/nature02043.

Fehr, E., Bernhard, H., \& Rockenbach, B. (2008). Egalitarianism in young children. Nature, 454, 1079-1083. https://doi.org/10.1038/ nature 07155

Greiner, B., \& Levati, M. V. (2005). Indirect reciprocity in cyclical networks: An experimental study. Journal of Economic Psychology, 26, 711-731. https://doi.org/10.1016/j.joep.2004.04.003.

Gummerum, M., Keller, M., Takezawa, M., \& Mata, J. (2008). To give or not to give: Children's and adolescents' sharing and moral negotiations in economic decision situations. Child Development, 79, 562 576. https://doi.org/10.1111/j.1467-8624.2008.01143.x.

Gummerum, M., Hanoch, Y., Keller, M., Parsons, K., \& Hummel, A. (2010). Preschoolers' allocations in the dictator game: The role of moral emotions. Journal of Economic Psychology, 31, 25-34. https://doi.org/10.1016/j.joep.2009.09.002.

Hamilton, W. D. (1964). The genetical evolution of social behavior I and II. Journal of Theoretical Biology, 7, 17-52. https://doi.org/10.1016/ 0022-5193(64)90039-6.

Harbaugh, W. T., \& Krause, K. (2000). Children's altruism in public good and dictator experiments. Economic Inquiry, 38, 95-109. https://doi. org/10.1111/j.1465-7295.2000.tb00006.x.

Herrmann, B., Thöni, C., \& Gächter, S. (2008). Antisocial punishment across societies. Science, 314, 1322-1327. https://doi.org/10.1126/ science.1165449.

House, B. R., Henrich, J., Brosnan, S. F., \& Silk, J. B. (2012). The ontogeny of human prosociality: Behavioral experiments with children aged 3 to 8. Evolution and Human Behavior, 33, 291-308. https://doi.org/10.1016/j.evolhumbehav.2011.10.007.

House, B., Henrich, J., Sarnecka, B., \& Silk, J. B. (2013). The development of contingent reciprocity in children. Evolution and Human Behavior, 34, 86-93. https://doi.org/10.1016/j.evolhumbehav.2012. 10.001

Kenward, B., \& Östh, T. (2015). Five-year-olds punish antisocial adults. Aggressive Behavior, 41, 413-420. https://doi.org/10.1002/ab. 21568.
Korsgaard, M. A., Meglino, B. M., Lester, S. W., \& Jeong, S. S. (2010). Paying you back or paying me forward: Understanding rewarded and unrewarded organizational citizenship behavior. Journal of Applied Psychology, 95, 277-290. https://doi.org/10.1037/ a0018137.

Krettenauer, T., Malti, T., Sokol, B. W., \& Laurier, W. (2008). The development of moral emotion expectancies and the happy victimizer phenomenon: A critical review of theory and application. European Journal of Developmental Science, 2, 221-235. https:// doi.org/10.3233/DEV-2008-2303.

Malti, T., Gummerum, M., \& Buchmann, M. (2007). Contemporaneous and one-year longitudinal prediction of children's prosocial behaviour from sympathy and moral motivation. Journal of Genetic Psychology, 168, 277-299. https://doi.org/10.3200/GNTP.168.3. 277-300.

Malti, T., Gummerum, M., Keller, M., \& Buchmann, M. (2009). Children's moral motivation, sympathy, and prosocial behavior. Child Development, 80, 442-460. https://doi.org/10.1111/j.14678624.2009.01271.x

Malti, T., Gummerum, M., Ongley, S., Chaparro, M., Nola, M., \& Bae, N. Y. (2015). "Who is worthy of my generosity?" Recipient characteristics and the development of children's sharing. International Journal of Behavioral Development, 40, 31-40. https://doi.org/10. 1177/0165025414567007.

McGuigan, N., Fisher, R., \& Glasgow, R. (2016). The influence of receiver status on donor prosociality in 6- to 11 -year-old children. Child Development, 87, 855-869. https://doi.org/10.1111/cdev. 12517.

Messer, E. J. E., Burgess, V., Sinclair, M., Grant, S., Spencer, D., \& McGuigan, N. (2017). Young children display an increase in prosocial donating in response to an upwards shift in generosity by a same-aged peer. Scientific Reports, 2633. https://doi.org/10.1038/ s41598-017-02858-y.

Moore, C. (2009). Fairness in children's resource allocation depends on the recipient. Psychological Science, 20, 944-948. https://doi.org/ 10.1111/j.1467-9280.2009.02378.x.

Neldner, K., Crimston, D., Wilks, M., Redshaw, J., \& Nielsen, M. (2018). The developmental origins of moral concern: An examination of moral boundary decision making throughout childhood. PLoS One, 13, e0197819. https://doi.org/10.1371/journal.pone.0197819.

Nowak, M. A., \& Roch, S. (2007). Upstream reciprocity and the evolution of gratitude. Proceedings of the Royal Society of London B, 274, 605-610. https://doi.org/10.1098/rspb.2006.0125.

Nowak, M. A., \& Sigmund, K. (1998). Evolution of indirect reciprocity by image scoring. Nature, 393, 573-577. https://doi.org/10.1038/ 31225 .

Nowak, M. A., \& Sigmund, K. (2005). Evolution of indirect reciprocity. Nature, 437, 1291-1298. https://doi.org/10.1038/nature04131.

Olson, K. R., \& Spelke, E. S. (2008). Foundations of cooperation in young children. Cognition, 108, 222-231. https://doi.org/10.1016/ j.cognition.2007.12.003.

Ongley, S. F., Nola, M., \& Malti, T. (2014). Children's giving: Moral reasoning and moral emotions in the development of donation behaviors. Frontiers in Psychology, 5, 1-8. https://doi.org/10.3389/ fpsyg.2014.00458.

Paulus, M., \& Moore, C. (2014). The development of recipient-dependent sharing behavior and sharing expectations in preschool children. Developmental Psychology, 50, 914-921. https://doi.org/10.1037/ a0034169.

Rutte, C., \& Taborsky, M. (2007). Generalized reciprocity in rats. PLoS Biology, 5, e196. https://doi.org/10.1371/journal.pbio.0050196.

Schmitz, E. A., Banerjee, R., Pouw, L. B. C., Stockmann, L., \& Rieffe, C. (2015). Better to be equal? Challenges to equality for cognitively able children with autism spectrum disorders in a social decision game. Autism, 19, 178-186. https://doi.org/10.1177/ 1362361313516547. 
Sebastián-Enesco, C., Hernández-Lloreda, M. V., \& Colmenares, F. (2013). Two and a half-year-old children are prosocial even when their partners are not. Journal of Experimental Child Psychology, 116, 186-198. https://doi.org/10.1016/j.jecp.2013.05.007.

Seinen, I., \& Schram, A. (2006). Social status and group norms: Indirect reciprocity in a helping experiment. European Economic Review, 50, 581-602. https://doi.org/10.1016/j.euroecorev.2004.10.005.

Thompson, C., Barresi, J., \& Moore, C. (1997). The development of future-oriented prudence and altruism in preschoolers. Cognitive Development, 12, 199-212. https://doi.org/10.1016/S08852014(97)90013-7.

Trivers, R. L. (1971). The evolution of reciprocal altruism. Quarterly Review of Biology, 46, 35-57. https://doi.org/10.1086/406755.

Trommsdorff, G., Friedlmeier, W., \& Mayer, B. (2007). Sympathy, distress, and prosocial behavior of preschool children in four cultures.
International Journal of Behavioral Development, 31, 284-293. https://doi.org/10.1177/0165025407076441.

Warneken, F., \& Tomasello, M. (2013). The emergence of contingent reciprocity in young children. Journal of Experimental Child Psychology, 116, 338-350. https://doi.org/10.1016/j.jecp.2013.06. 002.

Wellman, H. M., Cross, D., \& Watson, J. (2001). Meta-analysis of theory of mind development: The truth about false belief. Child Development, 72, 655-684. https://doi.org/10.1111/1467-8624. 00304.

Publisher's Note Springer Nature remains neutral with regard to jurisdictional claims in published maps and institutional affiliations. 